\title{
A ESTRADA DONA FRANCISCA \\ NA FormaÇÃo ECONÔMICA de SANTA CATARINA*
}

THE ROAD DONA FRANCISCA

IN THE ECONOMIC FORMATION SANTA CATARINA

Alcides Goularti Filho

alcides@unesc.net

RESUMO: O objetivo deste artigo é discutir a construção da Estrada Dona Francisca, no norte e no planalto norte de Santa Catarina, dentro da formação e da expansão do processo de colonização e do complexo ervateiro. O período abrange desde a fundação da Colônia Dona Francisca, em 1851, à conclusão das obras ferroviárias da Linha São Francisco, em 1913, ligando a cidade portuária de São Francisco do Sul à Rio Negro, passando por Joinville, São Bento do Sul e Rio Negrinho, seguindo o mesmo percurso da Estrada Dona Francisca. O texto está dividido em cinco tópicos. O primeiro traz uma breve introdução. Em seguida, discute o início da colonização do norte e do planalto norte catarinense, a partir da fundação da Colônia Dona Francisca. O terceiro tópico aborda a lenta construção da Estrada Dona Francisca, entre 1853 e 1895. No quarto, serão discutidas a colonização e a expansão demográfica, a partir da construção da Estrada em direção à Rio Negro. Por fim, uma breve conclusão destacando a sua integração comercial e produtiva na região.

PALAVRAS-CHAVE: Estrada; colonização; erva mate; integração; Santa Catarina.

ABSTRACT: The aim of this paper is to discuss the construction of Road Dona Francisca, in the north and north plateau of Santa Catarina, in the formation and expansion of the colonization process and the yerba mate complex. The period

\footnotetext{
Professor do Programa de Pós-Graduação em Desenvolvimento Econômico da UNESC. Doutor em Economia pela UNICAMP. Pesquisa financiada pelo MTCI/CNPq. 
stretching from the founding of Colônia Dona Francisca, in 1851, the works are completed railway line from San Francisco in 1913, linking the port city of South San Francisco to Rio Negro, through Joinville, Sao Bento do Sul and Rio Negrinho, following the same route of Road Dona Francisca. The text is divided into five topics. The first gives a brief introduction. Then we discuss the early settlement of northern and north plateau of Santa Catarina, from the founding of the Colonia Dona Francisca. The third topic discusses the slow construction of Road Dona Francisca, between 1853 and 1895. In the fourth, we discuss the colonization and population expansion, from the construction of the road towards Rio Negro. Finally, a brief conclusion highlighting its commercial and productive integration in the region.

KEYWORDS: Road; colonization; yerba mate; integration; Santa Catarina.

1. INTRODUÇÃO

A partir dos meados do século XIX, assistimos na economia e na sociedade brasileira ao início de um processo de modernização das estruturas produtivas com os adventos das ferrovias, da navegação a vapor e da expansão dos complexos agrário-mercantil exportador de café, ervamate, seringueira (borracha), algodão, cacau e couro. Dentro dos complexos regionais, foram criadas estruturas de beneficiamento, comercialização e transporte para atender às demandas do setor exportador. O caso mais exemplar foi o do complexo cafeeiro paulista, que acelerou o ritmo de acumulação na economia regional e imprimiu uma nova dinâmica na economia brasileira a partir do final do século XIX. A política imigratória financiada pelo governo, por um lado, estava dentro deste movimento de modernização econômica, uma vez que os imigrantes aumentariam a oferta de mão de obra para as lavouras de café. Por outro lado, deu início a uma nova política de colonização, amparada pelo Estado no Brasil meridional. O objetivo era fixar os imigrantes nas colônias para promoverem a prosperidade local, seja no Vale do Rio do Sino e na serra no Rio Grande do Sul, no norte, no sul e no Vale do Itajaí, em Santa Catarina, 
ou na região de Curitiba e nos vales dos rios Negro e Iguaçu, no Paraná. Em cada região, desenvolveram-se as condições materiais e sociais necessárias para a manutenção e a expansão da colonização.

Nesse período de modernização das estruturas produtivas, além da Estrada Dona Francisca (EDF), foi dado início à construção de três importantes estradas de caráter regional, que atendiam às demandas locais para escoar a produção e integrar a região aos portos litorâneos. A primeira foi a Estrada de Santa Clara, em Minas Gerais, cuja construção se iniciou em 1853, e levou três anos para ser concluída. As obras forma realizadas pela Companhia Comércio e Navegação do Mucuri, pertencente a Teófilo Ottoni, empresário mineiro que fundou a Colônia de Filadélfia (atual Teófilo Ottoni) no norte mineiro. A Estrada de Santa Clara, com 170 quilômetros, ligava a Colônia à localidade de Santa Clara (atual Nanuque), ponto em que o Rio Mucuri se tornava navegável até a sua foz no litoral.

A segunda foi a Estrada de Rodagem União e Indústria, construída entre os anos de 1856 e 1861, ligando as cidades de Petrópolis a Juiz de Fora, com 144 quilômetros, passando pela zona cafeeira do Paraíba. Foi a primeira estrada macadamizada no Império e a maior obra "rodoviária" do século XIX no Brasil. A estrada foi uma concessão privada, com garantia de juros, cedida a Mariano Procópio Ferreira Lage, proprietário da Companhia União e Indústria, a empresa responsável pela execução da obra (MATOS, 1995; NETTO, 1974).

A terceira obra foi a Estrada da Graciosa, ligando a cidade de Curitiba à vila portuária de Antonina. As obras iniciaram em 1853 e foram concluídas em 1873, com 29 quilômetros. A Estrada da Graciosa foi construída sobre uma trilha já conhecida desde o século XVIII, que ligava o planalto de Curitiba ao litoral, descendo a Serra do Mar, por onde era escoada a produção da erva-mate. Entre o planalto e o litoral paranaense também havia o Caminho do Arraial e o Caminho do Itupava, porém apenas a Graciosa foi macadamizada e transformada no principal eixo integrador do complexo ervateiro paranaense até os adventos da ferrovia (MOREIRA, 1975). 
Em Santa Catarina até os meados do século XIX, podemos destacar três estradas que integravam as principais vilas da província. A primeira era o caminho das tropas, que ligava Viamão a Sorocaba (Estrada da Mata - trecho entre Curitibanos e Rio Negro), passando por Lages e Curitibanos, integrava o planalto serrano com as feiras paulistas. A segunda era a Estrada do Litoral, que cortava todo o litoral catarinense, passando por Laguna, Desterro e São Francisco. Por último, a Estrada de Lages a Desterro, entre o planalto serrano e o litoral, que levou décadas para ser concluída e era a maior estrada dentro do território catarinense. Vale a pena destacar também o caminho que partia de Laguna a Lages, margeando o Rio Tubarão e subindo a íngreme Serra Geral, colocando o planalto serrano em contato com o litoral sul-catarinense (EHLKE, 1973; GOULARTI FILHO, 2007).

\section{COLONIZAÇÃO DO PLANALTO NORTE E NORDESTE CATARINENSE}

A colonização do norte de Santa Catarina começou com a experiência fourierista da Colônia Industrial de Sai, em 1842, formada por franceses, que ocuparam as margens da Baía da Babitonga, próximo a São Francisco do Sul. Porém, a experiência da Colônia não foi bem sucedida e, em 1864, já estava extinta (PIAZZA, 1994). O segundo processo colonizador na região foi o mais intenso e imprimiu um novo ritmo econômico e social à Província de Santa Catarina: a fundação da Colônia Dona Francisca, em 1851. Dentro dela, foi fundado o núcleo populacional de Joinville, que se transformou no centro irradiador da colonização na região. Era administrada pela "Sociedade Colonizadora de 1849 em Hamburgo", uma companhia alemã, que recebia subvenção do governo imperial para promover a entrada de imigrantes e realizar obras de expansão e melhoramentos para os colonos.

A Sociedade Colonizadora tinha interesse em expandir a colonização para o planalto norte catarinense, para fundar novas colônias e Hist. R., Goiânia, v. 19, n. 1, p. 171-196, jan./abr. 2014 
ampliar as possibilidades de acumulação do seu capital. Para a Sociedade Colonizadora, seria um "grande negócio" transformar uma economia natural em economia mercantil, pois criaria as condições para a sua reprodução econômica a favor da companhia. Além do mais, o governo imperial concedia as terras e dava subvenções para promover a colonização. Portanto, eram duas frentes de acumulação e valorização do capital da Sociedade Colonizadora.

A história da colonização da região já foi amplamente estudada por diversos memorialistas e pesquisadores, com enfoques sociais, econômicos, políticos e culturais. Não iremos repetir neste artigo as conclusões já obtidas nas várias pesquisas, mas apenas avançar no debate, introduzindo as contribuições de Rosa Luxemburgo e de Vladimir Lênin.

Parte do planalto norte catarinense, região também conhecida como Campos de São Miguel, até o início do último quartel do século XIX, era esparsamente povoado com a presença de pequenas vilas, formadas pela passagem dos tropeiros, como Mafra e Porto União, além de alguns aventureiros que exploravam a erva-mate na região, ou seja, tínhamos uma economia natural e um território de passagem. A situação começou a se reverter com a política de imigração, impulsionada pelo Estado, que visava demarcar território e defender fronteiras. Esta tarefa foi entregue à companhias capitalistas de colonização e à associações de trustes ferroviários. O crescimento virtuoso de Joinville, a abertura da Estrada Dona Francisca, a fundação de novos núcleos populacionais, a navegação dos rios Iguaçu e Negro, o início da exploração racional da erva-mate em território catarinense e a construção de estradas de ferro ocorrem num curto período de 25 anos, que transformou a região de uma economia natural numa economia mercantil. Foram criadas as condições materiais para a reprodução do capital, tendo como móvel da acumulação as atividades ervateiras.

Com relação à formação do mercado interno na região, é um equívoco classificar os colonos que chegaram ao Brasil como camponeses, pois já eram uma categoria social desintegrada na Europa pelo rápido 
processo de introdução das relações capitalistas no campo. No Brasil, os imigrantes não reproduziram as formas pretéritas do camponês autônomo, mas sim introduziram relações mercantis com base na pequena propriedade, no artesanato e na pequena oficina. Estavam dadas as condições concretas para fundar uma economia com uma ampla divisão social do trabalho.

Esta sociedade, pautada na pequena produção mercantil, de acumulação lenta, foi gerando nas suas entranhas os elementos concretos para a diferenciação social, em que alguns pequenos proprietários, comerciantes e artesãos se tornaram capitalistas prósperos e outros se arruinaram, seguindo o rumo da proletarização. Esta diferenciação criou as condições para a rápida transformação da mais valia em capital, acelerando o processo de acumulação. É a formação do mercado interno. Inicialmente, dado o pequeno volume de produção, o mercado tem uma abrangência local e regional e, com difusão da divisão do trabalho, a produção se amplia paralelamente com a necessidade de conquistar novos mercados. Neste segundo estágio, os transportes de média e longa distância dão sustentação ao fluxo mercantil.

\section{A leNTA CONSTRUÇÃO DA ESTRAdA DONA FRANCISCA}

As condições locacionais para a fundação da Colônia Dona Francisca está relacionada tanto a fatores geofísicos como econômicos. A presença do porto de São Francisco, do Rio Cachoeira - que era navegável até a Lagoa do Saguaçu, chegando à Baía da Babitonga - e a proximidade dos férteis campos de Curitiba e Lages foram fatores determinantes para a escolha do local para estabelecer a Colônia. Já era de conhecimento dos dirigentes da Colônia a possibilidade de alcançar os Campos de Curitiba por meio da Estrada Três Barras, e os Campos de Lages por picadas que avançavam pela Serra do Mar em direção a oeste. Serra acima, nascia 
"desenfreadamente" o "chá do Paraguai", que poderia ser transformando num "artigo comercial de extrema importância para as costas sul e oeste" (SOCIEDADE COLONIZADORA DE 1849 EM HAMBURGO, 1851, p. 10). Portanto, quando da escolha da localização da Colônia já se vislumbrava a articulação comercial com o planalto norte catarinense e o sudeste paranaense, de onde era extraída a erva-mate.

O bom desempenho da colonização no norte catarinense, atraindo mais imigrantes, estava condicionado à articulação comercial de Joinville com outras colônias, que tornou-se num centro consumidor da produção local e ao mesmo tempo fornecedora de insumos para a construção e a expansão da colonização na região. Afinal, a Sociedade Colonizadora era uma companhia capitalista que visava a valorização do seu capital. Portanto, ampliar as relações econômicas, transformando as economias naturais em mercantis, localizadas acima da serra ou mais ao sul de Joinville, era condição sine qua non para a valorização do capital da Sociedade Colonizadora.

Nós temos a intenção de colonizar sobretudo a oeste, avançando o quanto antes pela serra para o planalto de Lages e de Curitiba. A singular vantagem de a colônia fazer fronteira com esses distritos, nos quais ainda crescem plantas tropicais, possibilitará aos colonos uma garantia de venda de seus produtos não só por mar, mas também para o interior do país e, com a diversidade de produtos motivada pelo clima, o comércio nesta direção será proveitoso (SOCIEDADE COLONIZADORA DE 1849 EM HAMBURGO, 1852, p. 5).

Para o governo provincial e Imperial, a Colônia Dona Francisca cumpria os objetivos demográficos, mas, para a Sociedade Colonizadora, a razão da sua existência era a acumulação. Alargar as fronteiras territoriais e comerciais da Colônia significava buscar novas frentes de valorização, garantindo a sua existência. Neste sentido, era necessário abrir vias de comunicação em direção ao oeste e ao norte. Para o norte, em direção a Curitiba, foi aberta pela Sociedade Colonizadora uma ligação interna até a Estrada Três Barras. Em direção ao sul da província, chegando até Desterro, 
o contato poderia ser feito via navegação marítima ou por meio da antiga Estrada do Litoral.

Foram feitas algumas incursões de expedições, comandas por Karl August Wunderwald, engenheiro da Sociedade Colonizadora, em direção aos Campos de São Miguel, subindo a Serra do Mar, ao sul, em direção ao Vale do Itapocu, e ao encontro da Colônia Blumenau. A transposição da Serra do Mar em direção ao planalto norte por meio das antigas ramificações do Caminho do Peabiru, já era de conhecimento dos moradores de São Francisco. Em 1854, em direção ao oeste, Wunderwald definiu o melhor traçado por onde deveria passar uma estrada que iria garantir a expansão territorial e as trocas mercantis para a Colônia e a Sociedade Colonizadora:

Nas muitas investigações feitas na serra por parte da direção da colônia, no intuito de encontrar uma boa passagem pela serra, o geômetra da colônia Senhor Wunderwald provou ter uma resistência extremamente louvável para as penosas e difíceis condições desse trabalho, permanecendo a maior parte do tempo do ano, dia e noite, na floresta, para terminar a necessária análise do terreno com a menor perda de tempo possível (SOCIEDADE COLONIZADORA DE 1894 EM HAMBURGO, 1857, p. 10).

A Sociedade Colonizadora havia firmado com o governo imperial um contrato em 10 de março de 1856, que lhe daria o direito de adquirir "importantes propriedades no planalto", ao longo dos dois lados da futura estrada da serra a um preço de " $1 / 2$ Real por braça quadrada $\left[4,84 \mathrm{~m}^{2}\right]$ ", que, segunda a Sociedade Colonizadora, em pouco tempo estariam "muito valorizadas" (SOCIEDADE COLONIZADORA DE 1849 EM HAMBURGO, 1858, p. 4). Para tanto, a Sociedade Colonizadora disponibilizou para Wunderwald a quantia de 3:000\$000 mensais, para realizar a abertura de uma estrada ligando Joinville, partindo do seu porto fluvial, subindo a Serra do Mar, até o planalto norte da província, em direção ao Rio Negro, no Paraná ao encontro do Caminho de ViamãoSorocaba. 
Tendo como data oficial do início das obras da Serrastrasse (Estrada da Serra, como era conhecida a EDF) o dia 29 de março de 1858, a primeira frente de trabalho era formada por 40 trabalhadores. A estrada teria 30 palmos de largura (seis metros) e valetas abertas em ambos os lados (FICKER, 1965).

Em 10 de julho de 1858, a Sociedade Colonizadora assinou um novo contrato com o governo imperial, comprometendo-se a introduzir mais imigrantes na Colônia, dando-Ihes estruturas mínimas de reprodução social; em compensação, o governo financiaria a instalação dos novos imigrantes e faria outras benfeitorias, como concluir a construção da "Serrastrasse no período mais curto possível e gastar pelo menos Rs. 2.500\$000 mensais" (SOCIEDADE COLONIZADORA DE 1849 EM HAMBURGO, 1859, p. 4). Mais do que o início das obras, a possibilidade de abrir contatos comerciais com o planalto norte gerou expectativas favoráveis para a Colônia e a Sociedade Colonizadora: "abertura da Serrastrasse prevista para breve, deverá trazer resultados incalculáveis para a colônia" (SOCIEDADE COLONIZADORA DE 1849 EM HAMBURGO, 1860, p. 4).

Nos anos imediatos ao início da obras, o repasse do governo imperial atrasou, levando à lentidão e à paralisação das obras. Em 1862, a direção da Sociedade Colonizadora enviou à Corte um representante para tencionar o Ministério dos Negócios da Agricultura, Comércio e Obras Públicas a liberar os recursos prometidos para retomar as obras. A Sociedade Colonizadora tinha pressa, pois almejava tomar posse dos terrenos ao longo da estrada e começar a construção de ramais em direção ao vale do Itapocu e à Colônia de Blumenau. Para compensar a falta de recursos para as obras, o governo provincial resolveu liberar 2:000\$000 para os trabalhos de conservação do trecho já concluído (SANTA CATARINA, 1862). O problema era que os gastos aumentavam quanto mais próximo as obras chegavam da serra e com a manutenção dos trechos concluídos.

De acordo com o novo contrato, assinado em 1 을 de maio de 1865, quando a Estrada já alcançava 23,34 quilômetros macadamizados, a 
Sociedade Colonizadora se comprometeu a assumir as obras da EDF de acordo com o projeto definido pelo governo, que aumentava o repasse mensal para 5:000\$000. Em abril de 1867, foi realizado um novo contrato com prazo para mais cinco anos, garantindo $247 \mathrm{~km}^{2}$ de terras devolutas ao longo da Estrada para a Sociedade Colonizadora. Durante a Guerra do Paraguai (1864-1870), as obras da EDF seguiram num ritmo mais lento, sendo suspensas nos dois últimos anos. No mesmo período, a Sociedade Colonizadora tentava justificar-se das dificuldades em cumprir o contrato com o governo imperial de atrair mais imigrantes para a Colônia Dona Francisca.

Após o fim da Guerra, o governo imperial retomou as obras num ritmo mais contínuo. Mesmo com todo o esforço hercúleo para a sua construção, no ano de 1872 estavam efetivamente prontos apenas 35,5 quilômetros macadamizados, chegando até o alto da serra. $O$ restante eram picadas abertas e desmatadas, mas, como já era comum o trânsito de carroças e cargueiros, principalmente mais próximo de Joinville, constantemente era exigida das frentes de trabalho a manutenção dos trechos concluídos. As obras foram divididas em cinco distritos, somando ao todo 143,4 quilômetros, com largura entre as bordas externas das sarjetas de 6,8 metros, sendo que, na serra, chegava até cinco metros, com declive das rampas de $7,5 \%$, atingindo o ponto mais alto a 850 metros acima do nível do mar; caso fosse estendida até a Lagoa de Saguçu em Joinville, ela alcançaria 156 quilômetros. Em 1875, os cinco distritos eram os seguintes:

10 distrito - 24,5km, de Joinville até a subida da serra, empregava 606 trabalhadores,

2o distrito - 8,2 km, ficava na Serra do Rio Seco, empregava 103 trabalhadores,

3o distrito - $20 \mathrm{~km}$, segue da serra até a Encruzilhada, empregava 1.379 trabalhadores, 
40 distrito - 43,4 km, da Encruzilhada até Ribeirão da Serra, empregava 500 trabalhadores, subdividido em 4 seções:

- Da encruzilhada ao Rio Turvo, 13,3 km,

- Do Rio Turvo ao Rio Grande, $11,6 \mathrm{~km}$,

- Do Rio Grande a São Bento, 8,5 km,

- De São Bento ao ribeirão da serra, 10,0 km.

5o distrito - 47,3 km, da Encruzilhada seguia até a vila de Rio Negro, no Paraná, empregava 40 trabalhadores (RELATÓRIO ESTRADA DONA FRANCISCA, 1875).

Paralelos à construção da Estrada também estavam sendo abertos caminhos para o novo núcleo colonial de São Bento, que ficava nas margens da estrada, para onde foram contratados 716 trabalhadores. Portanto, em toda a extensão da estrada, mais os caminhos para São Bento, foram contratados 3.344 trabalhadores, um número muito expressivo para a época, haja vista que a população de Joinville, em 1872, era de 7.650 habitantes. Portanto, a construção da estrada com suas demandas de insumos, para construção de pontes e valas, ferramentas, equipamentos, alimentos, louças, vestimentas e calçados para as frentes de trabalho, rapidamente monetizava a região, principalmente Joinville, acelerando o processo de acumulação e impulsionando a abertura de novos núcleos coloniais.

Entre 1870 e 1875, as obras tiveram um avanço considerável, o traçado estava definido, as picadas foram abertas e desmatadas, faltando, apenas, fazer a ligação da estrada com o sistema de macadamização. Em 1876, restava concluir, apenas, 46 quilômetros macadamizados, e os núcleos de Campo Alegre, São Bento e Rio Negrinho já estavam servidos pela EDF, podendo a estrada ser transitada por carroças e carroções (BRASIL, 1877). Com o avanço das obras, o governo imperial cumpria a sua promessa de integrar a Colônia Dona Francisca ao planalto nortecatarinense, mas a Sociedade Colonizadora tinha dificuldades em acelerar o 
processo de colonização às margens da EDF, dada a baixa entrada de imigrantes.

O Relatório de 1878 da Sociedade Colonizadora traz um panorama geral da EDF:

Da Dona Francisca Strasse (Estrada Dona Francisca) havia 95 quilômetros transitáveis, mas nem toda a extensão estava macadamizada, e havia 30 quilômetros iniciados, que passam por São Bento, em direção a Rio Negro. A distância entre Joinville e São Bento é de 84 quilômetros, medindo-se pela rua, cujo trecho tem uma inclinação de cerca de 800 metros na passagem pela serra e que pode ser distribuída em um pequeno e regular declive; de acordo com todos os relatos que nos chegam, este trabalho foi resolvido da melhor maneira (SOCIEDADE COLONIZADORA DE 1849 EM HAMBURGO, 1878, p. 8).

Com a fundação da Colônia Agrícola de São Bento, em 1873, a EDF cumpria, parcialmente, seus objetivos para a região, e atendia aos anseios da Sociedade Colonizadora, que visava ampliar o seu raio de atuação, na busca de novos espaços de valorização. A conclusão do trecho até Rio Negro significaria a integração do litoral norte catarinense à região produtora de erva-mate.

Cada vez que as obras eram interrompidas, os custos de manutenção e de retomada eram maiores, principalmente com a perda da mão de obra preparada para enfrentar as intempéries de um ambiente inóspito. A recomendação dos agentes oficiais do Ministério era terminar o mais rápido possível a obra (BRASIL, 1875). Para cobrir as crescentes despesas, tanto de construção, como de manutenção, em agosto de 1874 o repasse mensal do Ministério dobrou, passando para 10:000\$000.

No ano de 1878, as obras em direção ao Rio Negro foram paralisadas no quilômetro 95, continuando apenas os serviços de manutenção e empedramento, construção de bueiros, pontes e pontilhões. Até 1885 , os trabalhos chegaram ao quilômetro 112,7 , com movimento de terra e condições de tráfego precárias. Mais adiante, do quilometro 130 até as margens do Rio Negro, era apenas um caminho de cargueiro, feito somente por tropas.

Hist. R., Goiânia, v. 19, n. 1, p. 171-196, jan./abr. 2014 
O Relatório da EDF de 1885 traz a seguinte conclusão sobre o seu estado geral:

A Estrada Dona Francisca oferece atualmente transito para os carros $112,7 \mathrm{~km}$, dos quais acham-se empedrados 87.760 metros. 0 estado geral da estrada, porém, não é satisfatório nos 57 primeiros quilômetros, e é necessário tratar desde já de renovar o empedramento em vários lugares, sob a pena de ver completamente estragados, em muito pouco tempo, os lugares que necessitam deste melhoramento (RELATÓRIO ESTRADA DONA FRANCISCA, 1886, p. 4).

Neste período, estavam empregados nas obras 667 trabalhadores, sendo 534 nos serviços de conservação, em que foram gastos 30:515\$143; 64 na reconstrução, e gastos 4:016\$862; e 69 em obras novas, e gastos 4:048\$388. Com a administração, foram gastos 9:857\$000, mais do dobro do gasto com obras novas. Esta distribuição de trabalhadores e recursos gastos em 1885 mostra a prioridade dada às obras na EDF, ou seja, à sua manutenção. Os recursos liberados pelo Ministério eram insuficientes para avançar com mais tenacidade em direção ao oeste, obrigando a administração da EDF a optar pela sua manutenção e exigir aumento nas verbas liberadas.

O crédito atual de 50:000\$000 é apenas suficiente para atender as reparações mais urgentes que exige a estrada na extensão de 112,7 $\mathrm{km}$ aberta ao transito dos carros; é portanto inútil pensar em prosseguir com este limitado crédito, em as obras novas de construção para o regular andamento das quais tornar-se-ia necessário um crédito de 150:000\$000 para o próximo exercício (RELATÓRIO ESTRADA DONA FRANCISCA, 1886, p. 9).

Para complicar a situação, as constantes chuvas nos mês de março, como foram as de 1884 e 1888, agravou a situação nos trechos não macadamizados. Os gastos com a recuperação dos trechos danificados pelas chuvas eram quase superiores aos gastos com obras novas, como em 1884 , quando foram despendidos $12: 000 \$ 225$ para reparar os estragos causados pelos temporais e 15:474\$0040 com obras novas de empedramento entre os quilômetros 102 a 130 (SANTA CATARINA, 1885). Esta situação se repetiu no ano de 1888 , quando as despesas com reparos 
consumiram $33,4 \%$ do total das subvenções. Portanto, se não fosse tomada uma medida mais enérgica para concluir as obras, os recursos liberados seriam, na sua maioria, absorvidos pela conservação da estrada (BRASIL, 1889). Além das chuvas intensas, o pesado tráfego feito pelas carroças e pelos carroções (São-bentowagen), carregados de erva-mate, que desciam até Joinville, também contribuíam para aumentar o desgaste da estrada. No ano de 1890, estavam empregados 670 trabalhadores no prolongamento e na conservação da estrada, e já haviam sido abertos 118 quilômetros de estrada (BRASIL, 1891).

Tabela 1: Número de trabalhadores na construção da Estrada Dona Francisca

\begin{tabular}{cc}
\hline Anos & Número de trabalhadores \\
\hline 1875 & 3.344 \\
1881 & 1.454 \\
1885 & 667 \\
1890 & 670 \\
\hline
\end{tabular}

Fonte: RELATÓRIO DA ESTRADA DONA FRANCISCA, 1876 e 1886; BRASIL, 1882; BRASIL, 1891.

No ano de 1892 , as verbas passaram para 100:000\$000 anuais, o que garantiria a conclusão das obras até Rio Negro. Neste ano, elas avançaram com empedramento até o quilômetro 112 e foram macadamizadas até o quilômetro 94, faltando, apenas, mais 34 quilômetros para chegar ao seu destino final (BRASIL, 1892). No ano seguinte, em 1893, dado o aumento dos valores repassados, as obras de empedramento chegaram até o quilometro 143, faltando, apenas, mais três quilômetros (BRASIL, 1894). Em função da Revolta Federalista em Santa Catarina, as obras foram temporariamente paralisadas. Por fim, no dia 31 de julho de 1895, foram dadas por concluídas pelo governo federal, que repassou a responsabilidade para o governo estadual (BRASIL, 1896). 
$\mathrm{Na}$ tabela abaixo, podemos acompanhar a evolução das despesas efetuadas na abertura da EDF, durante os anos de 1858 a 1892. Nota-se que a liberação aumenta mais entre os anos de 1873 a 1878 , quando as obras foram retomadas e aceleradas, passando de 35,5 para 95 quilômetros abertos e/ou macadamizados, respectivamente. Nos doze anos seguintes, há uma sensível redução dos repasses do Ministério, e as obras seguem num ritmo lento, avançando mais 13 quilômetros. Em 1892, são retomadas com mais vigor, quando os recursos liberados triplicam, chegando à sua conclusão em 1895, avançando 38 quilômetros em três anos, sendo 94 quilômetros macadamizados.

Tabela 2: Evolução dos gastos do governo (Império e República) com a Estrada Dona Francisca 1858-1892

\begin{tabular}{cccc}
\hline Anos & Gastos do Governo & Anos & Gastos do Governo \\
\hline 1858 & $5: 018 \$ 250$ & 1875 & $122: 092 \$ 000$ \\
1859 & $30: 103 \$ 506$ & 1876 & $136: 096 \$ 000$ \\
1860 & $34: 458 \$ 720$ & 1877 & $126: 092 \$ 000$ \\
1861 & $9: 258 \$ 905$ & 1878 & $113: 930 \$ 121$ \\
1862 & $21: 258 \$ 512$ & 1879 & $60: 000 \$ 000$ \\
1863 & $16: 203 \$ 024$ & 1880 & $60: 000 \$ 000$ \\
1864 & $28: 898 \$ 904$ & 1881 & $64: 492 \$ 000$ \\
1865 & $26: 346 \$ 367$ & 1882 & $60: 000 \$ 000$ \\
1866 & $43: 573 \$ 135$ & 1883 & $79: 999 \$ 543$ \\
1867 & $42: 768 \$ 838$ & 1884 & $79: 999 \$ 992$ \\
1868 & $48: 804 \$ 213$ & 1885 & $49: 999 \$ 958$ \\
1869 & $24: 831 \$ 717$ & 1886 & $49: 999 \$ 992$ \\
1870 & $19: 794 \$ 830$ & 1887 & $40: 999 \$ 996$ \\
1871 & $59: 533 \$ 180$ & 1888 & $44: 608 \$ 250$ \\
1872 & $51: 428 \$ 142$ & 1889 & $39: 338 \$ 355$ \\
1873 & $61: 888 \$ 000$ & 1892 & $130: 000 \$ 000$ \\
1874 & $97: 291 \$ 533$ & & \\
\hline
\end{tabular}

Fonte: SANTA CATARINA, 1888; BRASIL, 1890; BRASIL; 1893. 
Chegando à margem esquerda do rio Negro, onde mais tarde, em 1917, foi fundada a cidade de Mafra, a integração com a zona ervateira seria via fluvial, pelo Rio Negro, navegável até a sua foz, junto ao Rio Iguaçu, em Porto União e União da Vitória, passando por Canoinhas, importantes praças comerciais e de beneficiamento do complexo ervateiro. Mais acima do Rio Iguaçu, vinha a erva-mate, por via fluvial, de São Matheus e Porto Amazonas. Portanto, a EDF completaria um sistema de transporte dentro do complexo ervateiro: navegação fluvial (Iguaçu e Negro), estrada de rodagem (EFD), novamente a navegação fluvial em Joinville (Cachoeira) e porto de São Francisco. Dentro do fluxo mercantil do complexo ervateiro, a EDF cumpriria um papel determinante com via de comunicação para escoar a produção das áreas de plantio, passando pelos engenhos de beneficiamento até o porto.

Como Rio Negro, e mais tarde Mafra, estava no cruzamento com a Estrada da Mata (trecho do Caminho de Viamão-Sorocaba), a conclusão da EDF servia também às Províncias do Rio Grande do Sul e São Paulo, colocando em contato o comércio dos tropeiros com o complexo ervateiro e as cidades catarinenses serra abaixo.

Tabela 3: Evolução da construção da Estrada Dona Francisca 1860-1893

\begin{tabular}{c|c|c}
\hline Anos & Situação da obra & km construídos \\
\hline 1860 & & 16,17 \\
1863 & & 21,89 \\
1865 & Trecho macadamizado & 23,34 \\
1868 & & 31,90 \\
1872 & & 35,50 \\
1876 & & 46,00 \\
\hline 1878 & & 95,00 \\
1882 & Trechos abertos e & 101,00 \\
1885 & macadamizados & 112,70 \\
1890 & & 118,00 \\
1893 & & 146,00 \\
\hline
\end{tabular}


Fonte: SANTA CATARINA, diversos relatórios da Província; BRASIL, diversos relatórios do Ministério da Agricultura, Comércio e Obras Públicas.

Após a conclusão das obras, a responsabilidade de manutenção passou para o governo estadual, que, por sua vez, a compartilhou com as prefeituras municipais. No ano de 1904, a EDF foi definida como "rede estratégica da União", sob o comando do Ministério da Guerra, que, em tese, passaria a ser o responsável pela sua manutenção (BRASIL, 1905). Mesmo assim, não isentou o governo estadual e as prefeituras municipais de continuarem fazendo os serviços de manutenção. Nos anos de 1905 e 1906, sob o comando da 37a Infantaria, começou um trabalho de recuperação geral da estrada, sendo empregados 20 homens, com um orçamento de 18:000\$000, para 1905, e 150:000\$000, para 1906 (BRASIL, 1906, 1907). Em 1907, foram realizadas mais obras intensivas de reparos, desta vez compartilhadas com os municípios de Joinville, Campo Alegre e São Bento.

Contudo, dada a insuficiência orçamentária das prefeituras, o governo estadual assumia os trecho mais críticos, como o do quilômetro 53 a 75 (SANTA CATARINA, 1908). No município de São Bento foram utilizados dez trabalhadores para fazer os serviços de reparos (FOLHA DE PAGAMENTO, 1907).

Após o repasse da responsabilidade para o governo estadual, o tesouro catarinense passou a liberar recursos para a manutenção da EDF, que, constantemente, passava por situações de calamidade. Na tabela abaixo, podemos acompanhar a queda na evolução dos gastos com a conservação da EDF, principalmente após 1912, quando foi aberto o trecho ferroviário entre São Francisco do Sul e Mafra, da Linha São Francisco. 
Tabela 4: Evolução dos gastos do governo estadual com a conservação da EDF 1899 a 1918

\begin{tabular}{cc}
\hline Anos & Gastos do governo estadual \\
\hline 1899 & $56: 000 \$ 000$ \\
1902 & $60: 000 \$ 000$ \\
1903 & $47: 749 \$ 330$ \\
1905 & $61: 470 \$ 795$ \\
1909 & $53: 021 \$ 750$ \\
1910 & $51: 506 \$ 997$ \\
1912 & $33: 134 \$ 268$ \\
1914 & $12: 000 \$ 000$ \\
1915 & $19: 020 \$ 769$ \\
1916 & $18: 000 \$ 000$ \\
1918 & $18: 000 \$ 000$ \\
\hline
\end{tabular}

Fonte: SANTA CATARINA, vários anos.

Com a entrada em operação da Linha São Francisca, ramal da Estrada de Ferro São Paulo-Rio Grande, ligando São Francisco do Sul a Mafra, passando por Joinville, São Bento do Sul e Rio Negrinho, em 1913, a EDF tornou-se numa via secundária na região, tanto para o transporte de pessoas, como de mercadorias.

\section{ColONIZAÇÃO E EXPANSÃO DEMOGRÁFICA NAS MARGENS DA ESTRADA}

Com a conclusão parcial da obras da EDF, chegando até o 3 은 distrito, em direção à Encruzilhada nos Campos de São Miguel, a Sociedade Colonizadora começou os trabalhos de ocupação dos $247 \mathrm{~km}^{2}$ de terras, cedidas pelo governo para fins de colonização. A partir de uma leva de novos imigrantes que subiram a EDF, foi fundada, em 1873, a Colônia Agrícola de São Bento, às margens do rio de mesmo nome. Assim também ocorreu com Campo Alegre, onde já havia alguns moradores locais e que 
passou a ser ocupada, mais intensamente, por novos imigrantes, impulsionados pela ação da Sociedade Colonizadora. O mesmo veio a ocorrer, mais tarde, com a comunidade de Rio Negrinho, fundada em 1875, que ficava a quinze quilômetros do núcleo populacional de São Bento. Em função do impulso gerado pela fundação da Colônia Agrícola de São Bento, pelo fluxo mercantil que passava pela EDF e por estar dentro do complexo ervateiro, Campo Alegre e Rio Negrinho, ambos desmembrados de São Bento, passaram a fazer parte deste eixo colonizador do planalto norte catarinense. Descendo em direção ao Rio Itapocu, alguns colonos deixaram São Bento e fundaram o núcleo de Jaraguá, no ano de 1876.

A expansão da colonização, o aumento demográfico, a construção de vias de comunicação e o crescimento das atividades ervateiras monetizaram o planalto norte catarinense e criaram as condições materiais favoráveis para a formação de um mercado interno. Uma região de economia natural, que se metamorfoseou numa economia mercantil simples, criou uma base pulverizada com a presença da pequena produção mercantil, cuja acumulação, capitaneada pelo complexo ervateiro, desdobrou-se numa economia de reprodução ampliada. Estas condições materiais reforçaram a desintegração dos "camponeses" que chegavam da Europa para colonizar a região. Produzir e vender mercadorias, inclusive a própria força de trabalho, eram as condições necessárias para a reprodução da vida social.

A construção da EDF possibilitou a colonização no planalto norte, dos Campos de São Miguel, onde foi implantado um sistema baseado na pequena produção mercantil, cujos proprietários eram camponeses desintegrados. Foram gestadas formas avançadas de relações sociais com o intuito de produzir e comercializar mercadorias. Para a Sociedade Colonizadora, fazia sentido apenas colonizar nos moldes capitalistas.

Quando a Sociedade Colonizadora fundou a Colônia Agrícola de São Bento, já havia, em Joinville, onze fábricas de tijolos, duas olarias, vinte e uma fábricas de cigarro, três cervejarias, três fábricas de vinagre, uma marcenaria, uma fábrica de velas, uma fábrica de sabão, três curtumes 
e sete serrarias. Com relação às profissões, havia: trinta e oito marceneiros, trinta carpinteiros, treze ferreiros, seis latoeiros, trinta e quatro alfaiates, trinta e cinco sapateiros, seis curtidores, sete seleiros, sete padeiros, dez açougueiros, trinta charuteiros, doze moleiros, oito serralheiros, três tipógrafos, dezesseis carroceiros, doze barqueiros, três farmacêuticos, dez taberneiros, cinco tamanqueiros, quinze costureiras, dois construtores navais, dois torneiros, dois forjadores de cobre, dois relojoeiros, dois oleiros e dois saboeiros. Neste mesmo ano, foram produzidas 3.500 arrobas de açúcar, 275 pipas de rum, 4.000 medidas de melado, 37.500 alqueires de arroz, 400 alqueires de feijão, 36.800 alqueires de milho, 4.000 arrobas de tabaco, 2.500 arrobas de araruta e 700 arrobas de café (SOCIEDADE COLONIZADORA DE 1849 EM HAMBURGO, 1873). Portanto, Joinville, que tinha uma população de 6.810 habitantes em 1873, reunia as características de uma cidade capitalista, servia como um "padrão de colonização bem sucedido".

Campo Alegre, cuja povoação começou em 1807, tinha apenas um estabelecimento comercial, também começou a receber colonos, após a chegada da EDF. Em 1887, já havia as seguintes atividades fabris: um engenho de beneficiar erva-mate, uma olaria, uma padaria, uma selaria, duas ferrarias e três marceneiros. No comércio, havia nove casas comerciais, um açougue e um hotel. Destas casas comerciais, sete mantinham relação direta com o Rio de Janeiro. No início do século XX, dada a expansão do complexo ervateiro, já eram cinco engenhos de ervamate (HERBST, 1994). Na localidade de Rio Negrinho, no começo da sua colonização, em 1880, já havia casas comerciais, hotelarias e sapatarias. No princípio do século XX, já eram quatro engenhos de erva-mate (KORMANN, 1980).

A Colônia Agrícola de São Bento, no ano de 1883, já contava com cinco engenhos de erva-mate, três olarias e quatro cervejarias. Quatro anos mais tarde, o total de engenhos de erva-mate passou para dez, e havia onze olarias, doze cervejaria, além de surgirem mais quatro curtumes, uma selaria, três sapatarias, seis padarias, um alfaiate, um açougue, quatro 
hotéis e duas farmácias (SOARES, 1992). No ano de 1894, já havia oito serrarias, quatro curtumes, quatro selarias, oito marcenarias, quatro carpintarias, seis tanoeiros, doze ferreiros, três funilarias e doze sapatarias. Neste mesmo ano, foram produzidos 20.000 alqueires de centeio, 50.000 de milho, 1.100 de feijão, 500 de batata inglesa e 200 de cevada (FICKER, 1973). No quadro abaixo, podemos acompanhar a evolução da população nas cidades de Joinville e São Bento do Sul, entre 1857 e 1887. Ambas cresciam demograficamente, dada a constante entrada de novos imigrantes, que se estendeu até o início do século XX, e ao fluxo migratório de colonos e brasileiros provenientes de outras regiões.

Tabela 5: Evolução da população de Joinville e São Bento do Sul 1857-1887

\begin{tabular}{ccc}
\hline Anos & Joinville & São Bento do Sul \\
\hline 1857 & 1.700 & \\
1867 & 4.667 & \\
1877 & 9.049 & 2.376 \\
1887 & 16.150 & 9.850 \\
\hline
\end{tabular}

Fonte: Sociedade Colonizadora de Hamburgo

Com a extinção da Sociedade Colonizadora em 1897, suas ações foram incorporadas pela recém-fundada Sociedade Colonizadora Hanseática, companhia alemã fundada com o objetivo de ampliar a colonização no interior de Santa Catarina. No Vale do Itajaí, onde já havia a Colônia de Blumenau, a Hanseática fundou as Colônias de Harmonia (que se desdobrou nos atuais municípios de Ibirama, Presidente Getúlio, Witmarsun e Dona Emma) e Hansa (Corupá), e passou a gerenciar a entrada de novos imigrantes na região.

Em larga medida, a colonização do Vale do Itajaí, do nordeste e do planalto norte catarinense foi capitaneada por essas duas companhias que eram subsidiadas pelo Estado, seja no transporte dos imigrantes, na concessão de terras devolutas e no financiamento da infraestrutura de transporte. $\mathrm{Na}$ área de transportes, podemos destacar as subvenções 
concedidas à Companhia de Navegação Fluvial a Vapor Itajahy-Blumenau, e a garantia de juros repassados à Estrada de Ferro Santa Catarina e à Linha São Francisco da EFSPRG, e a construção da EDF.

\section{CONCLUSÃO}

A presença da pequena produção mercantil e da pequena oficina de artesanato, que produzia peças e ferramentas para o trabalho cotidiano, combinada com a rápida expansão do complexo ervateiro, criou as condições para a acumulação regional. O transporte da erva-mate pela EDF, utilizando carroções carregados de barricas e suas demandas de fabrico e consertos, impulsionou o crescimento de ferrarias, selarias e tornearias (fábricas de barricas). O complexo ervateiro exercia o papel de comando, liderando o processo de acumulação. O desdobramento desta acumulação foi sendo absorvido pela pequena produção mercantil, que prosperou e criou as condições necessárias para formar uma base econômica especializada, diversificada e integrada.

A produção da erva-mate criou um mercado para a expansão do complexo ervateiro, com a presença de engenhos, fábricas de barricas, carroções, ferrarias, casas comerciais, companhias de navegação e outros. Comerciantes, que atuavam na compra e venda de mercadorias em geral, passaram a se dedicar também ao comércio da erva-mate. A presença de engenhos e casas comerciais em toda a região criou elos de integração produtiva e comercial, ampliando as relações mercantis e possibilitando diversificar o capital. É a metamorfose do capital agrário mercantil para o industrial, pequenos capitalistas que prosperaram e dinamizaram a região, criando condições de "prosperidade" econômica regional.

Anexo 1: Mapa da Estrada Dona Francisca entre Joinville e Rio Negro 


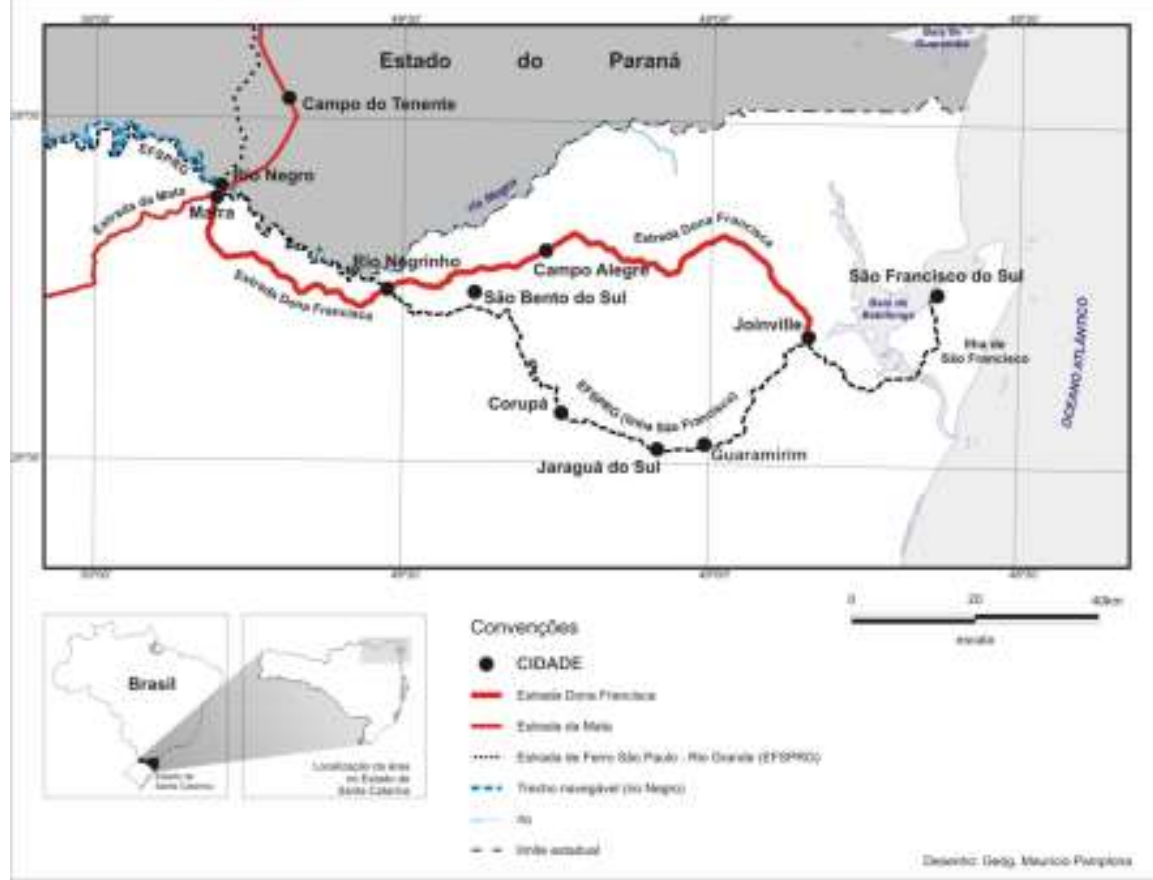

FONTES E REFERÊNCIAS BIBLIOGRÁFICAS

RELATÓRIOS OFICIAIS

BRASIL. Relatório do Ministério dos Negócios da Agricultura, Comércio e Obras Públicas apresentado pelo Ministro Francisco do Rego Barros Barreto à Assembléia Geral Legislativa. Rio de Janeiro, 1875. Disponível em <http://www.crl.edu > Acesso em agosto de 2009.

- Relatório do Ministério dos Negócios da Agricultura, Comércio e Obras Públicas apresentado pelo Ministro Thomaz José Coelho de Almeida à Assembléia Geral Legislativa. Rio de Janeiro, 1877. Disponível em <http://www.crl.edu >. Acesso em agosto de 2009. 
- Relatório do Ministério dos Negócios da Agricultura, Comércio e Obras Públicas apresentado pelo Ministro Manuel Alves Araújo à Assembléia Geral Legislativa. Rio de Janeiro: Tipografia Nacional 1882. Disponível em <http://www.crl.edu >. Acesso em agosto de 2009.

- Relatório do Ministério dos Negócios da Agricultura, Comércio e Obras Públicas apresentado pelo Ministro Rodrigo Augusto da Silva à Assembléia Geral. Rio de Janeiro: Imprensa Nacional, 1889. Disponível em $<$ http://www.crl.edu >. Acesso em agosto de 2009.

- Relatório do Ministério dos Negócios da Agricultura, Comércio e Obras Públicas apresentado pelo Ministro Francisco Glicério ao Chefe do Governo Provisório. Rio de Janeiro: Imprensa Nacional, 1890. Disponível em <http://www.crl.edu >. Acesso em agosto de 2009.

- Relatório do Ministério dos Negócios da Agricultura, Comércio e Obras Públicas apresentado pelo Ministro Barão de Lucena à Assembléia Geral. Rio de Janeiro: Imprensa Nacional, 1891. Disponível em <http://www.crl.edu >. Acesso em agosto de 2009.

. Relatório do Ministério dos Negócios da Agricultura, Comércio e Obras Públicas apresentado pelo Ministro Antão Gonçalves de Farias à Assembléia Geral. Rio de Janeiro: Imprensa Nacional, 1892. Disponível em <http://www.crl.edu >. Acesso em agosto de 2009.

- Relatório do Ministério dos Negócios da Agricultura, Comércio e Obras Públicas apresentado pelo Ministro Antonio Francisco de Paula Souza ao Vice-Presidente da República. Rio de Janeiro: Imprensa Nacional, 1893. Disponível em <http://www.crl.edu >. Acesso em agosto de 2009.

. Relatório do Ministério dos Negócios da Agricultura, Comércio e Obras Públicas apresentado pelo Ministro Bibiano Sérgio Marcelo da F. Castallat à Assembléia Geral. Rio de Janeiro: Imprensa Nacional, 1894. Disponível em <http://www.crl.edu >. Acesso em agosto de 2009.

- Relatório do Ministério dos Negócios da Indústria e Obras Públicas apresentado pelo Ministro Antônio Olyntho dos Santos Pires à Assembléia Geral. Rio de Janeiro: Imprensa Nacional, 1896. Disponível em $<$ http://www.crl.edu >. Acesso em agosto de 2009.

- Relatório do Ministério da Guerra apresentado pelo General Francisco de Paula Argollo ao Presidente da República. Rio de Janeiro: Imprensa Nacional, 1905. Disponível em <http://www.crl.edu >. Acesso em agosto de 2009. 
- Relatório do Ministério da Guerra, apresentado pelo General Francisco de Paula Argollo ao Presidente da República. Rio de Janeiro: Imprensa Nacional, 1906. Disponível em <http://www.crl.edu >. Acesso em agosto de 2009.

- Relatório do Ministério da Guerra apresentado pelo General Hermes Rodrigues da Fonseca ao Presidente da República. Rio de Janeiro: Imprensa Nacional, 1907. Disponível em <http://www.crl.edu >. Acesso em agosto de 2009.

RELATÓRIO DA ESTRADA DONA FRANCISCA. Relatórios dos trabalhos executados na Estrada Dona Francisca no ano de 1874. Joinville, 1875.

- Relatórios dos trabalhos executados na Estrada Dona Francisca no ano de 1885. Joinville, 1886.

SANTA CATARINA. Relatório do Presidente da Província João Francisco de Souza Coutinho apresentado à Assembléia Legislativa Provincial. Desterro: Tipografia Desterrense de J. J. Lopes, 1862. Disponível em <http://www.crl.edu >. Acesso em agosto de 2009.

- Relatório do Desembargador João Rodrigues Chaves apresentado ao 3o Vice-Presidente da Província Joaquim Augusto do Livramento. Desterro: Gabinete Tipográfico, 1885. Disponível em <http://www.crl.edu >. Acesso em agosto de 2009.

- Relatório do Presidente da Província Francisco José Rocha apresentado à Assembléia Legislativa Provincial. Rio de Janeiro: Tipografia União de A. M. Coelho da Rocha \& C., 1888. Disponível em $<$ http://www.crl.edu >. Acesso em agosto de 2009.

- Relatório do Vice-Governador Vidal José de Oliveira Ramos Júnior apresentado ao Congresso Representativo. Florianópolis: Tipografia da Livraria Moderna, 1904. Disponível em <http://www.crl.edu >. Acesso em agosto de 2009.

- Relatório do Governador Gustavo Richard apresentado ao Congresso Representativo. Joinville: Tipografia Boehm, 1908. Disponível em <http://www.crl.edu > Acesso em agosto de 2009.

DOCUMENTOS MANUSCRITOS

FOLHAS DE PAGAMENTOS. Trabalhadores da Estrada Dona Francisca. Prefeitura Municipal de São Bento do Sul, 1907.

RELATÓRIO SOBRE O ESTADO DA COLÔNIA DONA FRANCISCA. Joinvile, 1868 e 1870. (Manuscrito). 
SOCIEDADE COLONIZADORA DE 1849 EM HAMBURGO. Relatórios da Direção da Sociedade Colonizadora de 1849 em Hamburgo. Hamburgo, 1851-1892 (série completa traduzida por Tradução Helena Remina Richlin, do Arquivo Histórico de Joinville.

REFERÊNCIAS BIBLIOGRÁFICAS

FICKER, Carlos. História de Joinville: subsídios para a crônica da Colônia Dona Francisca. Joinville: Ipiranga, 1965.

. São Bento do Sul: subsídio para a sua história. Joinville: Ipiranga, 1973.

GOULARTI FILHO, Alcides. Formação econômica de Santa Catarina. Florianópolis: Editora da UFSC, 2007.

HERBST, Eugênio J. Subsídio para a história de Campo Alegre. Joinville: Ipiranga, 1994.

KORMANN, José. Rio Negrinho que eu conheci. Rio Negrinho: Editora do Autor, 1980.

. Histórico da Estrada Dona Francisca: de Joinville por Campo Alegre, São Bento do Sul e Rio Negrinho a Mafra. Florianópolis: Editora do Autor, 1989.

MATOS, Odilon Nogueira de. Vias de comunicação. In: HOLANDA, Sérgio Buarque. História geral da civilização brasileira: o Brasil monárquico declínio e queda do império. Rio de Janeiro: Bertand, v. 6, tomo II, 1995.

MOREIRA, Júlio Estrela. Caminhos das comarcas de Curitiba e Paranaguá: até a emancipação da Província do Paraná. Curitiba: Imprensa Oficial, v. 1 e 2, 1975.

NETTO, Francisco Ferreira. 150 anos de transportes no Brasil 1822-1972. Rio de Janeiro: CEDOP, 1974.

PIAZZA, Walter. A colonização de Santa Catarina. Florianópolis: Lunardelli, 1994.

PRADO JÚNIOR, Caio. Formação do Brasil contemporâneo. São Paulo: Brasiliense, 1996.

TERNES, Apolinário, VICENZI, Herculano. Dona Francisca Imperial Estrada da Serra. Joinville: Letra d'Água, 2001.

SOARES, Maria Elita. São Bento do Sul: sua história, seus documentos. São Bento do Sul: Prefeitura Municipal de São Bento do Sul, 1992. 